\title{
Effect of Harvesting Date and Variety of Date Palm on Antioxidant Capacity, Phenolic and Flavonoid Content of Date Palm (Phoenix Dactylifera)
}

\author{
Odeh I. , Al-Rimawi F. ${ }^{1, *}$, Abbadi J. ${ }^{2}$, Obeyat L. ${ }^{1}$, Qabbajeh M. ${ }^{1}$, Hroub A. ${ }^{3}$ \\ ${ }^{1}$ Chemistry Department, Faculty of Science and Technology, Al-Quds University, Jerusalem, Palestine \\ ${ }^{2}$ Biology Department, Faculty of Science and Technology, Al-Quds University, Jerusalem, Palestine \\ ${ }^{3}$ Beit-Jala Pharmaceutical Company, Beit-Jala, Palestine \\ *Corresponding author: falrimawi@science.alquds.edu
}

Received June 09, 2014; Revised August 05, 2014; Accepted August 14, 2014

\begin{abstract}
The effect of date palm variety and harvesting date on total phenolic content, total flavonoid content, and antioxidant capacity of seven varieties of date palm fruits collected at different maturation stages obtained from date palm farms located in the Jericho area of the Jordan valley was investigated in this study. During different harvesting times (from June to September 2011), total phenolic content, total flavonoid content, and antioxidant capacity varied between $13.75-231.40 \mathrm{mg}$ gallic acid equivalents (GAE), 1.72-9.6 mg catechin equivalents, and 142.0-719.3 $\mu \mathrm{mol}$ Trolox equivalents per $100 \mathrm{~g}$ dry weight sample for the seven varieties of date palm, respectively. Pearson correlation indicated that there is a strong significant correlation between antioxidant capacity and total phenolic content, as well as between antioxidant capacity and total flavonoid content for all date palm varieties investigated in this study. It is expected that these results will be useful to farmers particularly in their selection of harvesting time of the date palm fruits with high content of the bioactive compounds to meet the increasing demand on such healthy products.
\end{abstract}

Keywords: date palm antioxidant capacity, date palm phenolic content, date palm flavonoid content, harvesting date, date palm variety, phoenix dactylifera

Cite This Article: Odeh I., Al-Rimawi F., Abbadi J., Obeyat L., Qabbajeh M., and Hroub A., "Effect of Harvesting Date and Variety of Date Palm on Antioxidant Capacity, Phenolic and Flavonoid Content of Date Palm (Phoenix Dactylifera)." Journal of Food and Nutrition Research, vol. 2, no. 8 (2014): 499-505. doi: 10.12691/jfnr-2-8-11.

\section{Introduction}

The Date Palm (Phoenix dactylifera) tree is an important dietary source, with the global production of date fruits in 2011 was around 7.303 million tons [1]. The date palm fruit is an important component of the diet in most arid and semiarid regions particularly in the Middle Eastern countries. Date fruits are an excellent source of phenolics and therefore possess an extremely high antioxidant capacity [2]. Interest in phytochemical content and antioxidant capacity of date palms is increasing in recent years. Phenolic compounds are plant secondary metabolites, which play important roles in protection against disease and pests [3,4]. Date fruits have been reported to contain various phenolic acids, such as protocaechuic, p- hydroxy benzoic, vanillic, syringic, caffeic, coumaric, ferulic, hydroxy benzoic, hydroxyl cinnamic acids, which contribute significantly to the antioxidant capacity of date palms [5]. The latter compounds are believed to play an important role as a health protecting factor. Scientific evidence suggests that utilizing diets rich in antioxidants reduce the risk of chronic diseases including cancer and heart malfunction [5]. The main characteristic of antioxidant compounds is their ability to scavenging free radicals such as peroxide, hydroperoxide or lipid peroxyl and thus inhibits the oxidative mechanisms that lead to degenerative diseases [5].

Abundant literature dealing with effect of date palm variety, maturity stage, harvesting date and other parameters, on the antioxidant capacity, total phenolics and flavonoids contents. Vayalil [6], Biglari, Al Karkhi, and Easa [7], as well as Ardekani, Khanavi, Hajimahmoodi, Jahangiri, and Hadjikhoondi, [8] have studied the effect of date palm varieties from Iran on antioxidant capacity and total phenolic compounds of different varieties of date palm fruits. Mansouri, Embarek, Kokkalou, and Kefalas [9] have investigated the phenolic profile and the antioxidant capacity of different varieties of Algerian ripe date palm fruit. Al-Farsi, Alasalvar, Morris, Baron, and Shahidi, [10], Al-Farsi, Alasalvar, AlAbid, Al-Shoaily, Al-Amry, and Al-Rawahy, [11], as well as Singh, Guizani, Essa, Hakkim, and Rahman, [12] have studied the effect of date palm on the total flavonoids content, total phenolics content and antioxidant capacity of different palm date varieties from Oman. Allaith, [13] studied the effect of both date palm variety and maturity 
stages on the antioxidant capacity, and total phenolics content of sixteen cultivars of date palm grown in Bahrain at different ripening stages. Saafi, El Arem, Issaoui, Hammami, and Achour, [14] evaluated the total phenolics content and the antioxidant capacity of four date palm fruit varieties grown in Tunisia. A study that deals with the antioxidant capacity, phenolic and flavonoid contents of date palms fruits from Palestine, as well as the effect of date palm varieties and harvesting date has not been reported previously. The objectives of this study are therefore to determine the antioxidant capacity (AC), total phenolic content (TPC) and total flavonoid content (TFC) of methanolic extracts from seven different cultivars of date palm fruit at different harvesting times. AC, TPC, and TFC were assayed using FRAP, Folin-Ciocalteau, and aluminum chloride colorimetric methods, respectively. The determination of the concentration of different individual phenolic compounds (Gallic acid, phydroxybenzoic acid, Vanillic acid, Caffeic acid, Syringic acid, Ferulic acid, and Sinapic acid) was performed using HPLC. The correlation between antioxidant capacity and total phenolic content as well as between antioxidant capacity and total flavonoid content was also investigated in this study.

\section{Materials and Methods}

\subsection{Palm Date Material}

Fruits of seven date palm cultivars were investigated in this study; Zahedi, Barhi Balade, Barhi Iraqi, Madjhool, Rutab, Ahmar Balade, and Asfar Balade. Date samples (1.0 Kg each) were collected at different maturity stages (18 ${ }^{\text {th }}$ of June, $24^{\text {th }}$ of July, $4^{\text {th }}$ and $20^{\text {th of }}$ September 2011), and stored in the freezer at $-15{ }^{\circ} \mathrm{C}$ for later analysis. All cultivars were grown in Jericho/Palestine. For each extraction, $100 \mathrm{~g}$ of palm dates was used. Three replicates were carried out and the results were tabulated as average \pm SD (SD: standard deviation).

\subsection{Chemicals and Reagents}

2,4,6-tripyridyl- S-triazine (TPTZ), hydrochloric acid $37 \%(w / w)$, sodium hydroxide, ferric chloride trihydrate, ferrous sulfate heptahydrate, potassium persulphate, sodium acetate, sodium carbonate, sodium nitrite, aluminum chloride, methanol, Folin-Ciocalteu reagent, Trolox (6-hydroxy-2,5,7,8-tetramethylchroman-2carboxylic acid), gallic acid, p- hydroxybenzoic acid, vanillic acid, caffeic acid, syringic acid, ferulic acid, catechin, were obtained from Sigma-Aldrich company. All chemicals and reagents were of analytical grade.

FRAP reagent was prepared according to Benzie and Strain (1999) by the addition of $2.5 \mathrm{~mL}$ of a $10 \mathrm{mM}$ tripydyltriazine (TPTZ) solution in $40 \mathrm{mM} \mathrm{HCl}$ plus 2.5 $\mathrm{mL}$ of $20 \mathrm{mM} \mathrm{FeCl} \cdot 6 \mathrm{H}_{2} \mathrm{O}$ and $25 \mathrm{~mL}$ of $0.3 \mathrm{M}$ acetate buffer at $\mathrm{pH}$ 3.6. Acetate buffer $(0.3 \mathrm{M})$ was prepared by dissolving $16.8 \mathrm{~g}$ of acetic acid and $0.8 \mathrm{~g}$ of sodium hydroxide in $1000 \mathrm{~mL}$ of distilled water.

\subsection{Extraction of Date Palm}

Extraction of phenolic and flavonoid compounds from date palm samples was done as described by Biglari et al.
[7]. The edible part of date palm fruits (100 g) was crushed and blended for 3 min using a blender. The date palm was then extracted with $300 \mathrm{~mL}$ of methanol/water $(4: 1, v / v)$ at room temperature for 5 hours using an orbital shaker. The extracts were then filtered and the supernatant was concentrated under reduced pressure at $40^{\circ} \mathrm{C}$ for 3 hours using a rotary evaporator to obtain the date palm methanol crude extract. The crude extract was kept in dark glass bottles at $-15^{\circ} \mathrm{C}$ until used for analysis.

\subsection{Measurement of Antioxidant Capacity by FRAP Assay}

The antioxidant capacity of date palm fruit extracts was determined using the method of ferric reducing/antioxidant power (FRAP) of Benzie and Strain [15]. Freshly prepared FRAP reagent $(3.0 \mathrm{~mL})$ were warmed at $37^{\circ} \mathrm{C}$ and mixed with $40 \mu$ l of date palm fruit extract and the reaction mixtures were later incubated at $37^{\circ} \mathrm{C}$. Absorbance at $593 \mathrm{~nm}$ was read with reference to a reagent blank containing distilled water which was also incubated at $37{ }^{\circ} \mathrm{C}$ for up to 1 hour instead of $4 \mathrm{~min}$. Aqueous solutions of known $\mathrm{Fe}^{+2}$ concentrations in the range of 2-5 $\mathrm{mM}$ were used for calibration, and it was found that this method is linear from $2-5 \mathrm{mM}$ of Fe $\mathrm{Fe}^{+2}\left(\mathrm{r}^{2}\right.$ of 0.996).

\subsection{Total Phenolic Content (Folin-Ciocalteau Assay)}

Total phenolics were determined using FolinCiocalteau reagents (Singleton \& Rossi, 1965) [16]. Date palm fruit extract or gallic acid standard (40 $\mu \mathrm{l})$ were mixed with $1.8 \mathrm{~mL}$ of Folin-Ciocalteu reagent (prediluted 10 -fold with distilled water) and allowed to stand at room temperature for $5 \mathrm{~min}$, and then $1.2 \mathrm{~mL}$ of sodium bicarbonate $(7.5 \%, \mathrm{w} / \mathrm{v})$ was added to the mixture. After standing for $60 \mathrm{~min}$ at room temperature, absorbance was measured at $765 \mathrm{~nm}$. Aqueous solutions of known gallic acid concentrations in the range of $10-500 \mathrm{mg} / \mathrm{L}$ were used for calibration, and it was found that this method is linear from 10-500 ppm with a correlation coefficient $r^{2}$ of 0.994 for the plot of absorbance vs. concentration of gallic acid. Results were expressed as mg gallic acid equivalents (GAE)/100 g sample.

\subsection{Total Flavonoid Content}

The determination of total flavonoids was performed according to the colorimetric assay of Kim et al. [17]. Distilled water ( $4 \mathrm{~mL}$ ) was added to $1 \mathrm{~mL}$ of date palm fruit extract in a test tube. Then, $0.3 \mathrm{~mL}$ of $5 \%$ sodium nitrite solution was added, followed by $0.3 \mathrm{~mL}$ of $10 \%$ aluminum chloride solution. Test tubes were incubated at ambient temperature for 5 minutes, and then $2 \mathrm{~mL}$ of $1 \mathrm{M}$ sodium hydroxide were added to the mixture. Immediately, the volume of reaction mixture was made to $10 \mathrm{~mL}$ with distilled water. The mixture was thoroughly mixed using test tube shaker and the absorbance of the pink color developed was determined at $510 \mathrm{~nm}$. Aqueous solutions of known catechin concentrations in the range of $50-100$ $\mathrm{mg} / \mathrm{L}\left(\mathrm{r}^{2}\right.$ of 0.997$)$ were used for calibration and the results were expressed as $\mathrm{mg}$ catechin equivalents (CEQ)/100 g sample. 


\subsection{Determination of Different Phenolic Compounds by HPLC with UV Detector}

The analysis of phenolic compounds in the date palm extracts was conducted by HPLC using a waters Atlantis C18 column (250 mm x 4.6 ID, $5 \mu \mathrm{m}$ ). Isocratic elution was carried out with a mobile phase consisting of water: methanol (82/18, v/v) containing $2 \%(\mathrm{v} / \mathrm{v})$ acetic acid at a flow rate of $1 \mathrm{~mL} / \mathrm{min}$. UV detector was used for detection of the phenolic compounds (gallic acid, p-hydroxybenzoic acid, vanillic acid, caffeic acid, syringic acid, ferulic acid, and sinapic acid) at $280 \mathrm{~nm}$. HPLC method for the determination of theses six phenolic compounds was confirmed in the range from $10-200 \mathrm{ppm}\left(\mathrm{r}^{2}>0.99\right)$. The injection volume for all samples was $20 \mu$ l. Identification of the phenolic compounds was based on retention times in comparison with standards. The quantitation was carried out using external standard method. The concentration of each of the phenolic compounds was calculated using peak area and the calibration curves obtained from the phenolic compound standard solution. The amount of phenolic compound was expressed as milligram per $100 \mathrm{~g}$ of dry date palm (mg/100 g DW).

\subsection{Statistical Analyses}

Three samples of date palm fruits of each treatment were independently analyzed in each sampling, and all of the determinations were carried out in triplicate. The results are expressed as means \pm standard deviations. All statistical analyses were carried out using SAS (SAS Institute Inc., Cary, USA, Release 8.02, 2001). Comparisons of means with respect to the influence of harvesting date for each palm cultivar and also in the same harvesting date within different cultivars were carried out using the GLM procedure, treating main factors (harvesting date and cultivar) separately using one-way analysis of variance (ANOVA). The Bonferroni procedure was employed with multiple t-tests in order to maintain an experiment-wise of $5 \%$.

Pearson correlations were calculated to test the relation between individual quality indicators with each one of the other quality indices. The NOMISS option was used in order to obtain results consistent with subsequent multiple regression studies.

\section{Results and Discussion}

\subsection{Antioxidant Capacity (FRAP assay)}

The antioxidant capacity of date palm fruits is attributed primarily to the presence of water soluble radical scavenging compounds particularly phenols and flavonoids. Many factors contribute to the amount of antioxidants present among them are the date palm variety, the extent of ripening and the geographical origin. Figure 1 shows the antioxidant capacity of the seven date palm cultivars as a function of harvesting time. As it is obvious from this figure, the harvesting time has an effect on the antioxidant capacity of the date palm varieties where significant differences $(p<0.05)$ between the antioxidant activities of all varieties were found for the four harvesting times (June, July, early and late September), indicated by different capital letters (A, B, C, and D) for each palm date variety separately. As it is seen also in Figure 1, palm date varieties differed significantly $(\mathrm{p}<$ 0.05 ) at each harvesting date, indicated by small letters (a, b, c, and d).

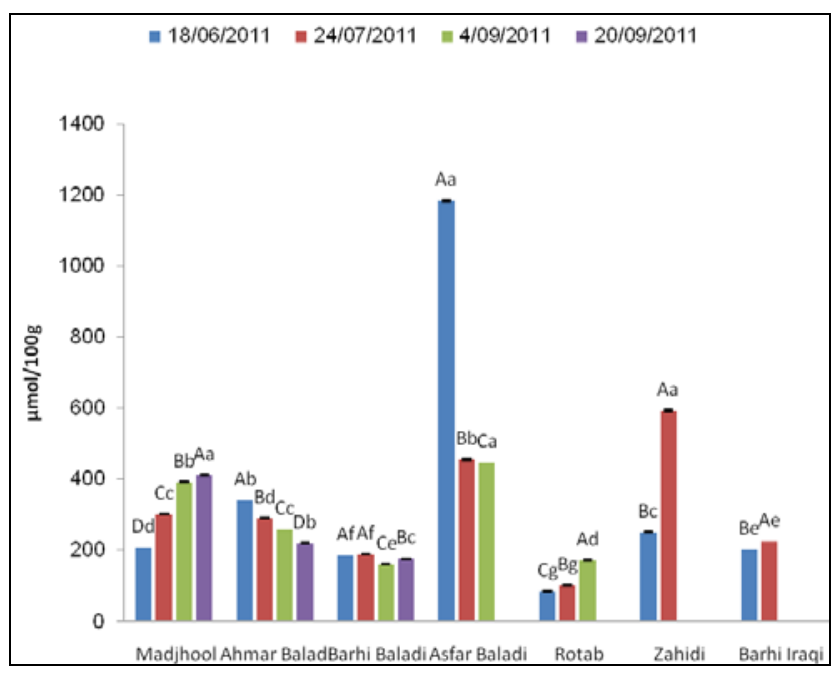

Figure 1. Antioxidant capacity (FRAP, $\mu \mathrm{mol} / 100 \mathrm{~g} \mathrm{DW}$ ) of different date palm cultivars obtained at different harvesting times. Error bars are standard deviations of three values

Figure 1 revealed that antioxidant capacity (AC) increased in Madjhool, Barhi Baladi, Rotab, Zahidi, and Barhi Iraqi cultivars, while decreased significantly in Ahmar Baladi and Asfar Baladi cultivars when compared in terms of postponing the date of harvest. The maximum value of Antioxidant capacity was found in Asfar baladi cultivar $(1184.7 \mu \mathrm{mol} / 100 \mathrm{~g} \mathrm{DW})$ at the first harvest (mid June), while the least was found in Rotab (84.4 $\mu \mathrm{mol} / 100$ $\mathrm{g}$ DW) in the first harvest (mid June). Antioxidant activities were increased dramatically in Madjhool with the delay of the harvest and its value was nearly doubled at the last harvest (late September). This quality parameter was also drastically decreased in Ahmar Baladi cultivar where it was reduced by $35 \%$ in the last harvest compared to the first harvest. The highest value of AC was detected in Asfar Baladi cultivar at the first harvest and only 38\% of its quantity was found in this cultivar in the second and third harvests. In Barhi Baladi cultivar, AC was marginally decreased with the delay of harvest and only $5 \%$ of this quality parameter was lost. In the other hand Rotab, Zahidi, and Barhi Iraqi cultivars showed a significant increase from first and last harvest in 105\%, $136 \%$, and $11 \%$ for mentioned cultivars respectively.

It is interesting also to study the effects of cultivar type (at specific harvesting time) on the antioxidant activities (Figure 1). As it is seen, significant differences of antioxidant activities were found within cultivar types at each harvesting time. At all harvesting dates of the fruits (from June to late September), all cultivars under study differ significantly in terms of antioxidant activities in their fruits (Figure 1). Asfar baladi cultivar was the superior (1184.7 $\mu \mathrm{mol} / 100 \mathrm{~g} \mathrm{DW})$, while Rotab was the inferior $(84.4 \mu \mathrm{mol} / 100 \mathrm{~g} \mathrm{DW})$, and the other cultivars ranged from $201-340 \mu \mathrm{mol} / 100 \mathrm{~g} \mathrm{DW}$. When the palm date cultivars were harvested in late July, the highest antioxidant capacity was reported in Zahidi, and the lowest was found also in Rotab, while the others contained from 224 to $592 \mu \mathrm{mol} / 100 \mathrm{~g}$ DW. The same response was reported in the third harvest in terms of 
superior and inferior cultivars. Only three cultivars were harvested in late September, and the highest content was found in Madjhool fruits, the lowest in Barhi baladi, while Ahmar baladi was intermediate.

\subsection{Total Phenolic Contents (TPC)}

Figure 2 shows the TPC of the seven date palm cultivars as a function of harvesting time. As it is obvious from this figure, the harvesting time has an effect on the TPC of the date palm varieties where significant differences $(p<0.05)$ between the TPC of all varieties were found for the four harvesting times (June, July, early and late September), indicated by different capital letters (A, B, C, and D) for each palm date variety separately. As it is seen also in Figure 2, Palm date varieties differed significantly $(\mathrm{p}<0.05)$ at each harvesting date, indicated by small letters (a, b, c, and d). Total phenolic contents increased in significant dramatic manner in Madjhool, Barhi Baladi, Rotab, Zahidi, and Barhi Iraqi cultivars, while decreased significantly in Ahmar Baladi and Asfar Baladi cultivars when compared in terms of postponing the date of harvest. The highest value (50.6 mg GAE/100 g DW) of this quality parameter was reported in Zahidi cultivar at the second harvest (late July) and the least content (8.8 mg GAE/100 g DW) was found in Barhi Baladi at the first harvest (mid June). TPC contents increased dramatically within increasing harvest time in most cultivars under investigation, and this increase was found 54\%, 80\%, 100\%, 150\%, and 20\% in Madjhool, Barhi Baladi, Rotab, Zahidi, and Barhi Iraqi cultivars respectively when the contents of the first harvest were compared with the last harvest in each cultivar separately. Conversely TPC content was reduced significantly in Ahmar baladi (31\% reduction) and Asfar baladi (78\% reduction).

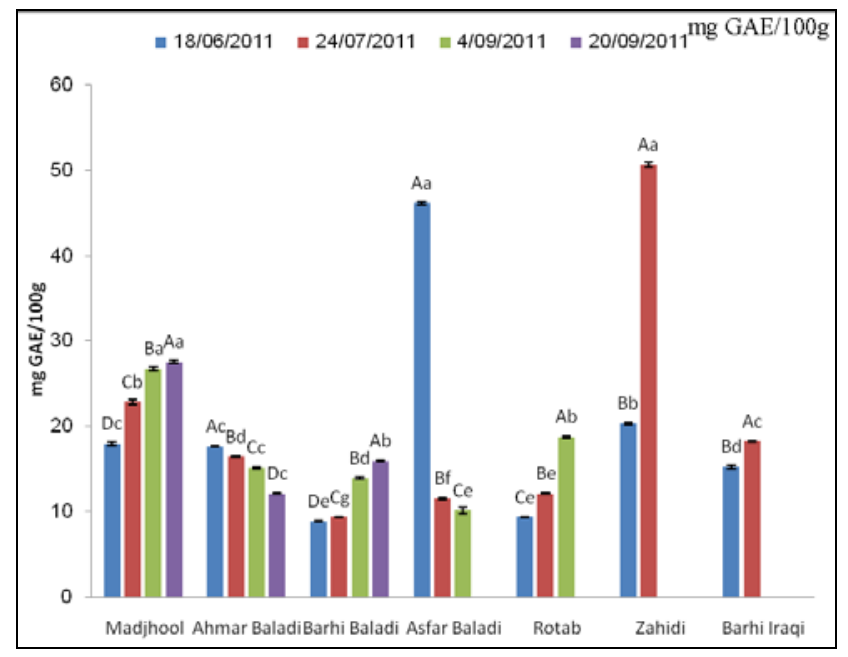

Figure 2. Total phenolic content (mg GAE/100g DW) of different date palm cultivars obtained at different harvesting times. Error bars are standard deviations of three values

It is interesting also to study the effects of cultivar type (at specific harvesting time) on the antioxidant activities (Figure 2). Results showed that at all harvesting times, all cultivars under study differ significantly in terms of total phenolic content (Figure 2), except for Madjhool and Ahmar Baladi, and for Barhi Baladi and Rotab when harvested in mid June where they showed no significant difference in their total phenolic contents. As in antioxidant capacity, Asfar baladi maintained the highest value of total phenolic content (46.1 mg GAE/100 g DW) when harvested early, while Bahri baladi and Rotab shared the lowest values (8.8, and $9.3 \mathrm{mg}$ GAE/100 g DW, respectively). The superior cultivar in terms of this quality parameter was Zahidi when fruits were cultivated in late July, while the inferior was Bahri baladi. Interestingly, Asfar baladi was the poorest in TPC contents when its harvest was delayed to early September as it was superior when harvested earlier in mid June. When harvested in late September, Madjhool was superior, while Ahmar baladi was inferior and Bahri baladi was intermediate.

\subsection{Total Flavonoid Content (TFC)}

The same statistical analyses were performed for total flavonoids content (TFC), and the results (Figure 3) showed that significant differences between total flavonoids content and the harvesting time were obtained for Madjhool, Asfar baladi, Rotab, Zahedi, and Barhi Iraqi. For Ahmar Baladi, significant differences were obtained for June, July, and September, but there were no significant differences between early and late September (Figure 3). For Barhi Baladi, significant differences were obtained for June, July, and late September, but there were no significant differences between July and early September. The values of total flavonoids content increased in a significant dramatic manner in all cultivars with increasing date of harvest except in Ahmar Baladi and Asfar Baladi cultivars in which the later cultivars showed a decrease in TFC content as date of harvest was delayed. In summary, for both Ahmar balade and Asfar balade date palm fruits, the highest flavonoid values were in June. This indicated that the drying process might have a destructive effect on these compounds [18].

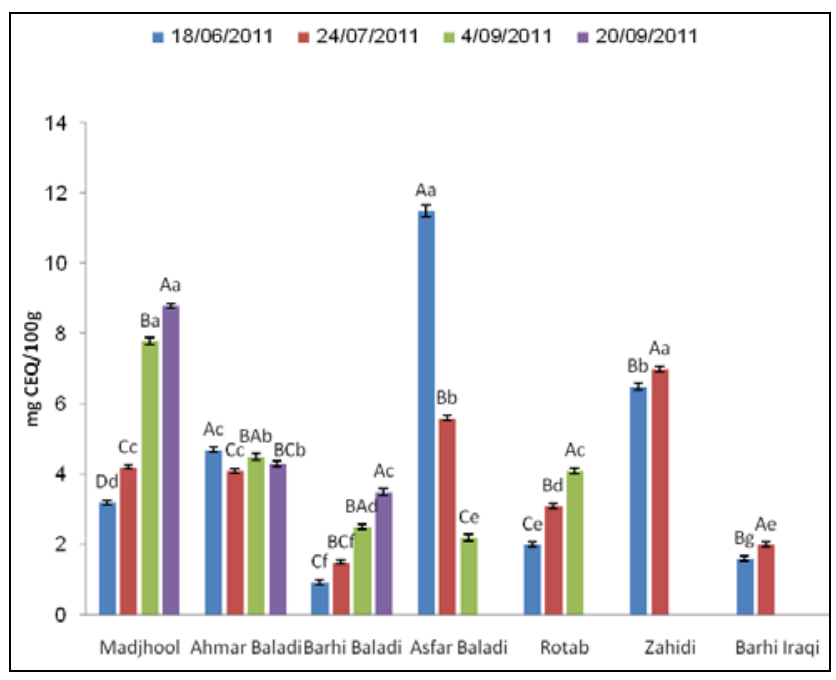

Figure 3. Total flavonoid content (mg CEQ/100g DW) of different date palm cultivars obtained at different harvesting times. Error bars are standard deviations of three values

The highest value of this quality index was reported in Asfar baladi cultivar when cultivated early, and this value decreased in this cultivar with delaying date of harvest. On the other hand the least value of total flavonoids content was measured in Barhi baladi in the earliest harvest date and its value was significantly increased when postponing the harvest date. Total flavonoids content of Madjhool fruits increased in $170 \%$ as the early and late harvests 
were compared. The contents of this quality parameter were only marginally decreased within delaying the harvesting of the fruits of Ahmar baladi cultivar. Asfar baladi fruits that contained the highest value of total flavonoids content compared to the other cultivars retained only $20 \%$ of the initial content when the harvest was delayed from mid June to early September, while Barhi baladi which contained the least value of TFC when harvested early but increased more than three times when their fruits were harvested in late September. Rotab cultivar doubled TFC fruits contents with postponing the harvest from mid June to early September, while the increase in this quality index was marginally improved as the harvest was delayed to late July as compared to mid June. For Zahedi and Barhi Iraqi, total flavonoids content has increased in $7 \%$ and $25 \%$, respectively as the early compared with the late harvest.

As in the case of antioxidant capacity and total phenolic content, the effect of cultivar type on total flavonoids content was also studied at four harvesting times. Results showed that at all harvesting times, all cultivars under study differ significantly in terms of total flavonoids content (Figure 3), except for Madjhool and Ahmar Baladi when harvested in July where they showed no significant difference in their total flavonoids content. Repeatedly, Asfar baladi proved its superiority in terms of total flavonoids content (Figure 3) when cultivated early as in the case of antioxidant capacity and total phenolic content, while Bahri baladi contained the least value of total flavonoids content. At the second harvest, Zahidi and Bahri baladi were the superior and inferior respectively. Contents of total flavonoids were the highest in the third and fourth harvests while the inferiors were Asfar baldi and Barhi baladi in the third and fourth harvests respectively.

\subsection{Pearson Correlation Analyses}

A correlation between antioxidant capacity and total phenolic content, between antioxidant capacity and total flavonoid content, as well as between total phenolic content and total flavonoid content was performed for all date palm varieties investigated in this study at different harvesting dates, see Table 1 , Table 2 . Table 1 reveals that all quality indices (antioxidant capacity with total phenolic content, antioxidant capacity with total flavonoids content, and total phenolic content with total flavonoids content) are highly and significantly correlated with each other in fruits of Madjhool, while in Ahmar baladi, only total flavonoids content and total phenolics content were highly and significantly correlated while the other compensation were not significant.

Table 1. Pearson coefficients between quality indices (antioxidant capacity (AC), total phenolic content (TPC) total flavonoids (TPC)) of Madjhool (above the diagonal) and Ahmar baladi (below the diagonal)

\begin{tabular}{|c|c|c|c|}
\hline Variables & $\mathrm{AC}$ & TPC & TFC \\
\hline $\mathrm{AC}$ & & $0.997 * * *$ & $0.961 * * *$ \\
\hline ТРС & $0.961 * * *$ & (1) & $0.945^{* * *}$ \\
\hline TFC & 0.436 & 0.344 & \\
\hline
\end{tabular}

Significance indicated as * for $\mathrm{p}<0.05$, ** for $\mathrm{p}<0.01$, and $* * *$ for $\mathrm{p}<$ $0.001, \mathrm{n}=12$.

Asfar baladi cultivar fruits show high significant correlation within all quality parameters when each one is correlated with every parameter under investigation (Table
2), while Bahri baladi shows a high significant positive correlation between TFC and TPC, the correlation was significantly negative between TPC and AC, and the correlation between TFC and AC was negative but not significant.

Table 2. Pearson coefficients between quality indices (antioxidant capacity (AC), total phenolic content (TPC) total flavonoids (TPC)) of Asfar baladi above diagonal and Bahri baladi below diagonal

\begin{tabular}{cccc}
\hline Variables & AC & TPC & TFC \\
\hline AC & - & $0.999^{* * *}$ & $0.935^{* * *}$ \\
TPC & $-0.709^{* *}$ & $-\overline{7}^{* * *}$ & $0.943^{* * *}$ \\
TFC & -0.550 & $0.917^{* *}$ & - \\
\hline \multicolumn{2}{l}{ Significance indicated as * for $\mathrm{p}<0.05,{ }^{* *}$ for $\mathrm{p}<0.01$, and ${ }^{* * *}$ for $\mathrm{p}<$} \\
$0.001, \mathrm{n}=12$.
\end{tabular}

Both Rotab and Zabedi cultivars (data not shown) showed a highly significant positive correlation between the quality indicators under study when the correlation was done within quality parameters of each cultivar separately. The correlation within the quality indices in the fruits of Bahri Iraqi cultivar (data not shown) was positive and highly significant.

All quality indices under investigation in Bahri Iraqi were highly and significantly inter-correlated. When the data of all cultivars were pooled, the three quality parameters under study show high significant positive correlation when each parameter was correlated with each of the other quality parameters (data not shown).

These results confirmed that antioxidant of dates palm arises from mainly phenolic compounds and flavonoids, and demonstrates the potential of Palestinian dates as antioxidant functional food ingredients. Similar results were obtained by Biglari et. al. [7] where they got a linear relationship between antioxidant capacity and total phenolic content or total flavonoid content. Similar results were obtained also by Neo Y-P. et. al. [19] where a high positive correlation was obtained between total phenolic content and FRAP antioxidant capacity assay with a correlation coefficient of 0.999 .

\subsection{Phenolic Compounds in the Date Palm Varieties Determined by HPLC}

Six phenolic compounds in the date palm extracts identified and quantified in this study (Table 3). Gallic acid, appears in most of the date varieties during maturity stages and the highest value was in Asafar balade date variety (1.02 mg/100 g DW), followed by Ahmar balade (0.49 mg/100 g DW), Barhi balade (0.27 mg/100 g DW), Rotab (0.24 mg/100 g DW), Medjool (0.082 mg/100 g DW), Zahedi (0.074 mg/100 g DW) and Barhi iraqi (0.067 mg/100 g DW). p-Hydroxybenzoic acid was the most dominant in all date varieties and recorded the highest concentration in dry date in Asfar balade $(2.8 \mathrm{mg} / 100 \mathrm{~g}$ DW) followed by $1.85 \mathrm{mg} / 100 \mathrm{~g}$ DW in Barhi balade variety, Barhi iraqi (1.23 mg/100 g DW), Rotab (1.20 mg/100 g DW), and Medjool (0.69 mg/100 g DW). Vanillic acid appears in the date fruits where the highest value was in Madjhool (0.46 mg/100 g DW), followed by Rotab (0.43 mg/100 g DW), Barhi Iraqi (0.26 mg/100 g DW), Barhi baladi (0.2 mg/100 g DW), Zahedi (0.14 mg/100 g DW), and Ahmar baladi (0.12 mg /100 g DW) (Table 3).

Caffeic acid appears in some palm date varieties and the highest value was in Ahmar baladi (1.45 mg/100 g DW) followed by Barhi Iraqi (0.056 mg/100 g DW) and 
Medjool (0.021 mg/100 g DW). Syringic acid appears in Barhi Iraqi as the highest value $(0.20 \mathrm{mg} / 100 \mathrm{~g} \mathrm{DW})$ followed by Ahmar baladi (0.19 mg/100 g DW), Barhi baladi (0.080 mg/100 g DW) and (0.035 mg/100 g DW) in
Zahedi. Ferulic acid appears only in Barhi baladi date variety and ranged from 0.041 to $0.52 \mathrm{mg} / 100 \mathrm{~g} \mathrm{DW}$, (Table 3).

Table 3. Amounts of phenolic compounds (mg/100 $\mathrm{g} \mathrm{DW}$ ) found in the seven date palm varieties harvested from June to late September 2011, determined by HPLC

\begin{tabular}{|c|c|c|c|c|c|c|c|}
\hline \multirow[b]{2}{*}{ Date palm variety } & \multirow[b]{2}{*}{ Harvesting date } & \multicolumn{6}{|c|}{ Content of phenolic compound (mg/100 g DW) } \\
\hline & & Gallic Acid & p-Hydroxy-benzoic Acid & Vanilic Acid & Caffeic Acid & Syringic Acid & Ferulic Acid \\
\hline \multirow[t]{4}{*}{ Madjhool } & $18 / 06 / 2011$ & n.d.* & n.d. & 0.46 & n.d. & n.d. & n.d. \\
\hline & $24 / 07 / 2011$ & 0.081 & 0.38 & 0.27 & n.d. & n.d. & n.d. \\
\hline & 04/09/2011 & n.d. & 0.56 & n.d. & 0.021 & n.d. & n.d. \\
\hline & 20/09/2011 & n.d. & 0.69 & n.d. & 0.017 & n.d. & n.d. \\
\hline \multirow[t]{4}{*}{ Ahmar balade } & $18 / 06 / 2011$ & 0.44 & 0.058 & n.d. & 0.026 & n.d. & n.d. \\
\hline & $24 / 07 / 2011$ & 0.49 & 0.12 & 0.11 & n.d. & 0.19 & n.d. \\
\hline & 04/09/2011 & 0.097 & 0.070 & n.d. & n.d. & n.d. & n.d. \\
\hline & 20/09/2011 & n.d. & n.d. & n.d. & 1.4 & n.d. & n.d. \\
\hline \multirow[t]{4}{*}{ Barhi balade } & $18 / 06 / 2011$ & 0.064 & 0.34 & 0.11 & n.d. & n.d. & 0.061 \\
\hline & $24 / 07 / 2011$ & 0.27 & 0.37 & 0.20 & n.d. & n.d. & 0.041 \\
\hline & 04/09/2011 & n.d. & 0.6 & n.d. & n.d. & n.d. & 0.49 \\
\hline & 20/09/2011 & n.d. & 1.9 & 0.063 & n.d. & 0.080 & 0.52 \\
\hline \multirow[t]{3}{*}{ Asfar balade } & $18 / 06 / 2011$ & 0.4 & 0.90 & n.d. & n.d. & n.d. & n.d. \\
\hline & 24/07/2011 & n.d. & 1.20 & n.d. & n.d. & n.d. & n.d. \\
\hline & 20/09/2011 & 1.02 & 2.8 & n.d. & n.d. & n.d. & n.d. \\
\hline \multirow[t]{3}{*}{ Rotab } & $18 / 06 / 2011$ & n.d. & n.d. & 0.25 & n.d. & n.d. & n.d. \\
\hline & $24 / 07 / 2011$ & 0.24 & 0.75 & 0.37 & n.d. & n.d. & n.d. \\
\hline & 20/09/2011 & n.d. & 1.1 & 0.43 & n.d. & n.d. & n.d. \\
\hline \multirow[t]{2}{*}{ Zahedi } & $18 / 06 / 2011$ & 0.035 & 0.026 & n.d. & n.d. & n.d. & n.d. \\
\hline & $24 / 07 / 2011$ & 0.074 & n.d. & 0.14 & n.d. & 0.035 & n.d. \\
\hline \multirow{2}{*}{ Barhi iraqi } & $18 / 06 / 2011$ & 0.067 & 0.51 & n.d. & 0.056 & n.d. & n.d. \\
\hline & 24/07/2011 & 0.048 & 1.20 & 0.26 & n.d. & 0.20 & n.d. \\
\hline
\end{tabular}

As seen in Table 3, gallic acid, p-hydroxybenzoic acid, vanillic acid and caffeic acid appeared in Madjhool date fruit. For gallic acid it appeared in July and the value was $0.081 \mathrm{mg} / 100 \mathrm{~g} \mathrm{DW}$ and then vanished, but for $\mathrm{p}$ hydroxybenzoic acid it ranged between 0.38 and 0.69 $\mathrm{mg} / 100 \mathrm{~g}$ DW from July to late September. Vanillic acid appeared in both June and July with values of 0.46 and $0.27 \mathrm{mg} / 100 \mathrm{~g} \mathrm{DW}$, respectively. While caffeic acid appeared in September and varies between 0.017 to 0.021 mg /100 g DW.

For Ahmar baladi date fruit it is obvious from Table 3 that the content of the phenolic compound gallic acid showed irregularity from June to September and ranged between 0.097 to $0.44 \mathrm{mg} / 100 \mathrm{~g}$ DW. The same for $\mathrm{p}-$ hydroxybenzoic acid which ranged between 0.058 to $0.070 \mathrm{mg} / 100 \mathrm{~g}$ DW. While vanillic acid and syringic acid appeared in July with $0.11 \mathrm{mg} / 100 \mathrm{~g}$ DW and 0.19 mg/100 g DW, respectively. Cafeic acid concentration increased from $0.026 \mathrm{mg} / 100 \mathrm{~g} \mathrm{DW}$ in June to 1.40 $\mathrm{mg} / 100 \mathrm{~g}$ DW in late September.

Barhi baladi HPLC chromatogram showed that Barhi baladi contained gallic acid in the range between 0.064 $\mathrm{mg} / 100 \mathrm{~g}$ DW in June and $0.27 \mathrm{mg} / 100 \mathrm{~g}$ DW in July, phydroxybenzoic acid in the range between 0.34 and 1.90 $\mathrm{mg} / 100 \mathrm{~g}$ DW from June to late September, vanillic acid ranged between 0.063 and $0.20 \mathrm{mg} / 100 \mathrm{~g} \mathrm{DW}$, ferulic acid ranged between 0.061 to $0.52 \mathrm{mg} / 100 \mathrm{~g} \mathrm{DW}$, and syringic acid value was $0.080 \mathrm{mg} / 100 \mathrm{~g} \mathrm{DW}$ ) in late September as seen in Table 3.

Gallic acid and p-hydroxybenzoic acid appeared in Asfar baladi date fruit and ranged between 0.40 and 1.02 $\mathrm{mg} / 100 \mathrm{~g} \mathrm{DW}$ for gallic acid, and 0.90 to $2.8 \mathrm{mg} / 100 \mathrm{~g}$ DW for p-hydroxybenzoic acid as seen in Table 3. Apparently in Rotab date fruit, gallic acid, phydroxybenzoic acid and vanillic acid appeared in the HPLC chromatogram in the range shown in Table 3. Gallic acid, p-hydroxybenzoic acid, vanilllic acid, and syringic acid phenolic compounds were appeared in Zahedi date fruit as shown in Table 3. While in Barhi Iraqi date fruit gallic acid, p-hydroxybenzoic acid, vanillic acid, caffeic acid and syringic acid appeared as shown in Table 3.

\section{Conclusions}

Total phenolic content, total flavonoid content, and antioxidant activities of date palm fruits collected from Palestine are affected by type of variety, and harvesting time. On the basis of these findings, it is concluded that date palm fruits from Palestine is a rich source of phenolics, flavonoid compounds and constitutes a natural source of potent antioxidants that may prevent many diseases and could potentially be used in food, pharmaceutical, cosmetic formulations. In depth study of the effect of processing time and methods used on the antioxidant constitution of date palm fruits particularly the most popular date palm in Palestine known as Madjhool should performed in the future.

\section{Acknowledgments}

We are grateful to Beit Jala pharmaceutical company for performing HPLC analyses in their laboratories.

\section{Statement of Competing Interests}

The authors have no competing interests.

\section{List of Abbreviations}

TPC: Total phenolic content 
TFC: Total flavonoid content.

AP: Antioxidant capacity

FRAP: ferric reducing/antioxidant power

TPTZ: 2,4,6-tripyridyl- S-triazine

GAE: Gallic acid equivalents

DW: dry weight

\section{References}

[1] FAO(2007).http://faostat.fao.org/site/567/DesktopDefault.aspx?Pa geID=567\#ancor, accessed on August, 20, 2013

[2] Eberhardt, M.V., Lee, C.Y. and Liu, R.H. "Antioxidant activity of fresh apples", Nature, 405. 903-904. 2000.

[3] Servili M., and Montedoro G. "Contribution of phenolic compounds in virgin olive oil quality". European Journal of Lipid Science and Technology; 104. 602-613 2002.

[4] Silva S., Gomes L., Leitão F., Coelho, A.V., and Vilas Boas L. "Phenolic Compounds and Antioxidant Activity of Olea europaea L. Fruits and Leaves". Food Sci Tech Int, 12 (5). 385-396. 2006.

[5] Prakash, A., Rigelhof, F. and Miller, E. "Antioxidant Activity. Available from World Wide Web": http://www.medlabs.com/downloads/antiox_acti_.pdf. 2011.

[6] Vayalil, P.K. "Antioxidant and antimutagenic properties of aqueous extract of date fruit (Phoenix dactylifera. L. Arecaceae)". Journal of Agricultural and Food Chemistry. 50. 610-617. 2002.

[7] Biglari, F., Al Karkhi, A.F.M. and Easa, A.M. "Antioxidant activity and phenolic content of various date palm (Phoenix dactylifera) fruits from Iran". Food Chemistry, 107. 16361641.2008.

[8] Ardekani., M., Khanavi, M., Hajimahmoodi, M., Jahangiri, M., and Hadjikhoondi, A. "Comparison of Antioxidant Activity and Total Phenol Contents of some Date Seed Varieties from Iran". Iranian Journal of Pharmaceutical Research, 9 (2). 141-146. 2010.

[9] Mansouri, A., Embarek, G., Kokkalou, E., and Kefalas, P. "Phenolic profile and antioxidant activity of the Algerian ripe date palm fruit (Phoenix dactylifera)". Food Chemistry. 89. 411-420. 2005.
[10] Al-Farsi, M., Alasalvar, C., Morris, A., Baron, M., and Shahidi, F. "Compositional and sensory characteristics of three native sundried date (Phoenix dactylifera L.) varieties grown in Oman". Journal of Agricultural and Food Chemistry. 53. 7586-7591. 2005a.

[11] Al-Farsi, M., Alasalvar, C., Al-Abid, M., Al-Shoaily, K., Al-Amry, M., and Al-Rawahy, F. "Compositional and functional characteristics of dates, syrups, and their by-products". Food Chemistry. 104. 943-947.2007.

[12] Singh, V., Guizani, N., Essa, M.M., Hakkim, F.L., and Rahman, M.S. "Comparative analysis of total phenolics, flavonoid content and antioxidant profile of different date varieties (Phoenix dactylifera L.) from Sultanate of Oman". International Food Research Journal. 19. 1063-1070. 2012.

[13] Allaith. A. A. "Antioxidant activity of Bahraini date palm (Phoenix dactylifera L.) Fruit of various cultivars". International Journal of Food Science and Technology, 43. 1033-1040. 2008.

[14] Saafi, E. B., El Arem, A., Issaoui, M., Hammami, M., and Achour, L. "Phenolic content and antioxidant activity of four date palm (Phoenix dactylifera L.) fruit varieties grown in Tunisia". International Journal of Food Science and Technolog, 44. 23142319. 2009.

[15] Benzie, I.F.F. and Strain, J.J. "Ferric reducing/antioxidant power assay: Direct measure of total antioxidant activity of biological fluids and modified version for simultaneous measurement of total antioxidant power and ascorbic acid concentration". Methods In Enzymology. 299. 15-27. 1999.

[16] Singleton, V.L., and Rossi, J.A. "Colorimetry of total phenolics with phosphomolybdic-phosphotungstic acid reagents". American Journal of Enology and Viticulture. 16. 144-158. 1965.

[17] Kim, D. O., Jeong, S. W., and Lee, C. Y. "Antioxidant capacity of phenolic phytochemicals from various cultivars of plums". Food Chemistry. 81. 321-326. 2003.

[18] Re, R., Pellegrini, N., Proteggente, A., Pannala, A., Yang, M., and Rice-Evans, C. "Antioxidant activity applying an improved ABTS radical cation decolorization assay". Free Radic. Biol. Med. 26. 1231-1237. 1999.

[19] Neo, Y. P., Ariffin, A., Tan, C. P. and Tan, Y. A. "Phenolic acid analysis and antioxidant activity assessment of oil palm (E. guineensis) fruit extracts". Food Chemistry. 122. 353-359. 2010. 